\title{
NUMERICAL SIMULATION OF THE MOVEMENT OF SMOOTH PARTICLES AT THE ELECTROMAGNETIC SEPARATORS WITH DRUM
}

\author{
TUDOR CĂSĂNDROIU ${ }^{1}$, GABRIELA VALERIA CIOBANU ${ }^{* 1,2}$, LIANA \\ ALEXANDRA VIŞAN ${ }^{2}$ \\ ${ }^{I}$ Faculty of Biotechnical Systems Engineering, University Politehnica of Bucharest, \\ Splaiul Independenţei no. 313, sector 6, Bucharest, Romania \\ ${ }^{2}$ National Institute of Research - Development for Machines and Installations Designed to \\ Agriculture and Food Industry - INMA, Ion Ionescu de la Brad, Bld. no. 6, Sector 1, \\ Bucharest, Romania
}

\begin{abstract}
The paper presents the main theoretical elements underlying the seeds separation process after their surface. During the seed cleaning and sorting process according to the surface condition machines with electromagnetic or magnetic separators drums are used. In this paper is made a comparative theoretical analyze of smooth seeds movement on electromagnetic drum surface and trajectory in free flight, neglecting and taking into consideration air resistance, detached from the separation drum and it is evaluated the collection area of detached seeds. On this basis, were carried out several case studies and numerical simulations for three different machines.
\end{abstract}

Keywords: seed movement, seed speed, seed trajectory, friction coefficient, numerical simulation

\section{INTRODUCTION}

Seed separation of parasitic weeds, especially for dodder, is almost impossible to obtain from the seed crop mass by conventional methods. For this reason were used the seed morphologic characteristics differences, especially for the dodder seed and crop seed tegument [1].

The dodder seeds, presented in Figures 1 and 2, have on the exterior surface small cavities and asperities, and the cultivated plant seeds have the smooth and shiny surface [2-4]. Due to this the differences, between this two categories of seeds, is outlined by mixing them with fine iron powder that adhere to the dodder seeds surfaces, and the cultivated plants seeds are clean. In this way, dodder seeds can be considered, particles with magnetic proprieties and the other paramagnetic. On this principle are working the magnetic and electromagnetic drum separators $[1,5,6]$.

Electromagnetic separator uses as main element an electromagnetic cylindrical drum, which works in horizontal position and has a rotation movement at a constant angular speed.

On the national and international level, experimental research is conducted to develop theoretical researches of the electromagnetic drum separators working process, in order to optimize these machines from the constructive and functional point of view.

\footnotetext{
${ }^{*}$ Corresponding author, email: gaby4n@yahoo.ro

(C) 2015 Alma Mater Publishing House
} 
To substantiate the experimental research, an important role it has the conducted theoretical research and mainly numerical simulations, for different movement conditions of smooth particles at the drum surface, and also in freefall neglecting or taking into consideration the air resistance.

The simulations presented in this paper, are based on finding appropriate mathematical models, presented in the papers $[7,8]$. However, also a comparative analyzes of the obtained results for different values of the seed movement parameters was made, and this is the objective of this paper.

The numerical simulation was carried out for several drum diameters and for several friction coefficient values, to establish the smooth seed movement on the rotational drum and free flight trajectory analyze neglecting and taking into consideration the air influence.

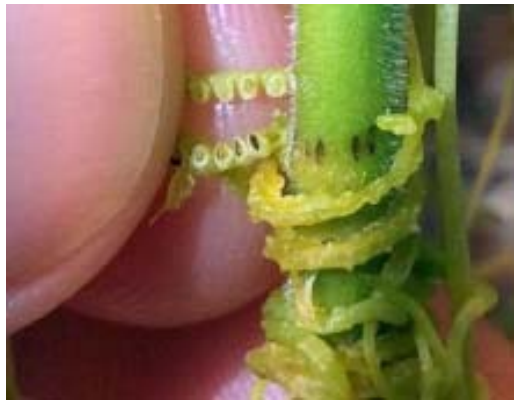

Fig. 1. Parasitic dodder plant [2].

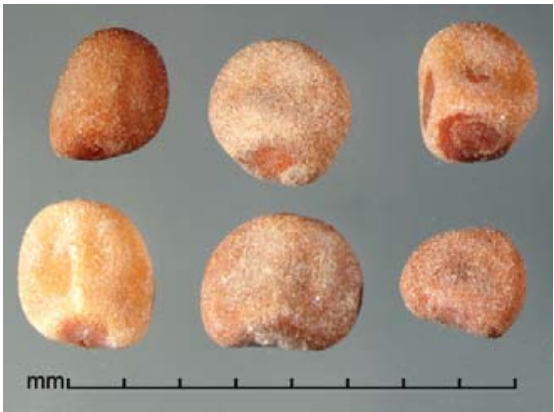

Fig. 2. Dodder seed external surface $[3,4]$.

\section{MATERIAL AND METHOD}

The electromagnetic separation machines work on the seed separation principle in function of seed external surface, which gain magnetic properties, due to their covering with fine iron powder, from the sowing paramagnetic material.

The separation feeding material is previously prepared, mixed with iron powder and water in the mixing chamber and then transported by an angled conveyor that supplies a vibrating table. This evenly distributes the seeding material on the rotating drum surface which is driven in a rotating movement, as it can see in Figure 3 .

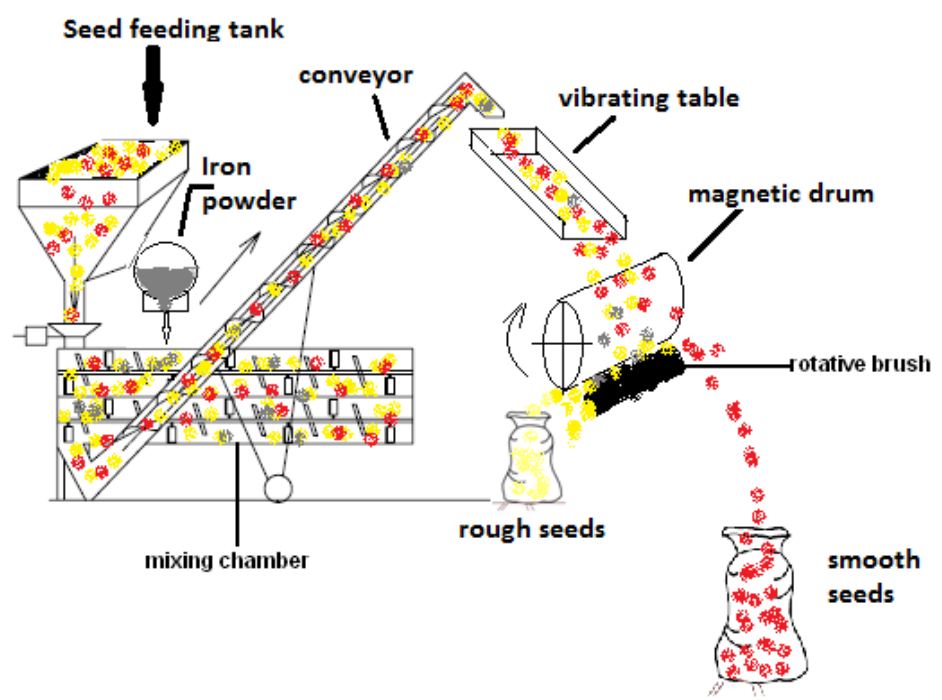

Fig. 3. Electromagnetic separation machine working process and seeding material flow.

Due to electromagnetic drum, that creates a magnetic field, the dodder seeds covered with iron powder are attracted and retained on drum surface, whereas the smooth seeds, on which is not attached the iron powder, 
remain free and roll directly on the drum surface, but those have the same direction as the drum rotation, when rich the detachment point these have a freefall motion in the air. In this way the seeds are separate collected depending on the detachment point, the dodder seed are later detach from the drum surface in the lower collector.

The numerical simulations were considerate the next cases.

\subsection{The smooth particle motion on drum surface}

The smooth seed motion on the drum surface, neglecting the air resistance, is taking place until it reaches the detachment angle and the detachment speed, from which determines the seed linear speed [7]. By numeric integration of no homogenous differential equation (1) of first grade were obtained the expression of coefficients $a, b$, and $c$, defined by equations (2) and (3).

$$
\begin{gathered}
\dot{\theta}^{2}=c \cdot e^{-2 \mu_{d} \theta}+\frac{2 \mu_{d} a+b}{1+4 \mu_{d}^{2}} \sin \theta+\frac{2 \mu_{d} b-a}{1+4 \mu_{d}^{2}} \cos \theta \\
a=\frac{2 g}{R} ; b=\frac{2 \mu_{d} g}{R} \\
c=\frac{a-2 \mu_{d} b}{1+4 \mu_{d}^{2}}
\end{gathered}
$$

The: $\mathrm{a}, \mathrm{b}$ and $\mathrm{c}$ are the integration constants that are established accordance with initial conditions.

In the case in which the particle has an accelerated motion with a higher speed than the peripheral speed of the drum, before drum detachment point, it can be used the equation (4), in which is introduced the value of $c_{I}$ coefficient, that has the expression presented din equation (5).

$$
\begin{gathered}
\dot{\theta}^{2}=c_{1} \cdot e^{2 \mu_{d} \theta}-\frac{2 \mu_{d} a+b}{1+4 \mu_{d}{ }^{2}} \sin \theta-\frac{2 \mu_{d} b-a}{1+4 \mu_{d}{ }^{2}} \cos \theta \\
c_{1}=\frac{a+2 \mu_{d} b}{1+4 \mu_{d}{ }^{2}}
\end{gathered}
$$

where: $R$ - drum radius; $g$ - the gravitational acceleration, $\mu_{d^{-}}$dynamic friction coefficient and $c_{l}$ - the integration constant, how's value is determinate from initial conditions $t=0, \dot{\theta}=0, \theta=0$ [1].

The accelerated seed motion when is slipping on the drum surface, is applied the equation (4) $\mu_{d}$ and is replaced with $\left(-\mu_{d}\right)[8]$.

\subsection{The smooth seed motion after drum detachment}

The smooth seed detachment from the magnetic drum it has a free movement that can be considerate similar to particle movement with an initial velocity under a certain angle from horizontal axis. For this reason, it can be used the equations (6), mathematical expression of particle movement when is neglected the air resistance [9].

$$
y=x \operatorname{tg} \theta_{0}+\frac{g\left(1+\operatorname{tg}^{2} \theta_{0}\right)}{2 v_{0}{ }^{2}} \cdot x^{2}
$$

where: $\theta_{0}$ - the seed detachment angle, $v_{0}$ - the seed detachment speed value. 
The equations (8) and (9) describe the particle trajectory when is taking into consideration the air resistance in parametric coordinates $x=x(\theta)$ and $y=y(\theta)$, in $x M_{0} y$ reference system as it can be observed in Figure 4. In this way can be established the particle detachment point from the drum and the $c^{*}$ coefficient can be calculated using the equations (9) and (10) [4].

$$
\begin{gathered}
x=\int_{\theta_{0}}^{\theta} \frac{d \theta}{g \cos ^{2} \theta\left\{\frac{k}{g}\left[\frac{\sin \theta}{\cos ^{2} \theta}+\ln \operatorname{tg}\left(\frac{\theta}{2}+\frac{\pi}{4}\right)\right]-c^{*}\right\}} \\
y=\int_{\theta_{0}}^{\theta} \frac{\operatorname{tg} \theta \cdot d \theta}{\cos ^{2} \theta\left\{\frac{k}{g}\left[\frac{\sin \theta}{\cos ^{2} \theta}+\ln \operatorname{tg}\left(\frac{\theta}{2}+\frac{\pi}{4}\right)\right]-c^{*}\right\}} \\
c^{*}=\frac{k}{g}\left[\frac{\sin \theta_{0}}{\cos ^{2} \theta_{0}}+\ln \operatorname{tg}\left(\frac{\theta_{0}}{2}+\frac{\pi}{4}\right)\right]-\frac{1}{v_{0}^{2} \cos ^{2} \theta_{0}} \\
\frac{k}{g}=\frac{1}{u_{p}{ }^{2}}
\end{gathered}
$$

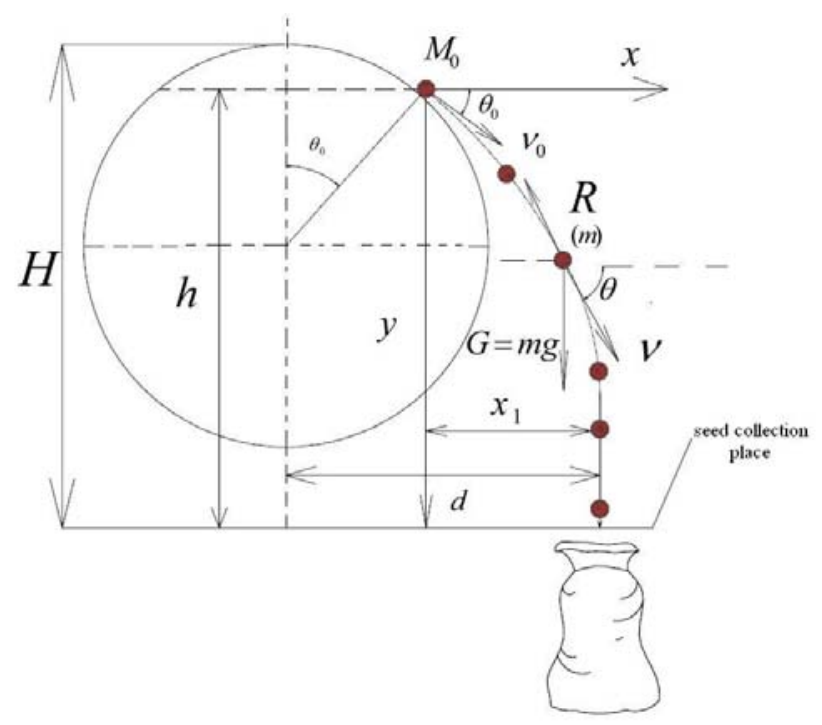

Fig. 4. The particle trajectory in free fall with air resistance [8].

Where: $\theta$ - particle angle when $y=h ; \theta_{0}$ - the drum detachment angle; $k$ - air resistance coefficient; $u_{p}$ - particle floating speed and $v_{0}=R \theta^{\prime}{ }_{0}$ - the linear seed speed.

Using the above model can be determinate the collecting position of the smooth seeds, respectively the $H$ and $d$ quotas values that are dependent on parameters $\theta_{0}, R$ and $x_{l}$, defined in equations (11) and (12).

$$
\begin{aligned}
& H=h+R \cdot\left(1-\cos \left(\theta_{0}\right)\right. \\
& d=R \sin \theta_{0}+x_{1}
\end{aligned}
$$

where: $\mathrm{d}$ - the position of the seed collector, $\mathrm{R}$ - drum radius, $\theta_{0}$ - the seed detachment angle, $\mathrm{x}_{1-}$ distance. 
Form equations (8) and the constructive conditions, when it is impose that $y=h$, is obtained the $\theta$ angle value, and from equations (7) is obtained the $x_{l}$, value, in this way can be estimated the collector position, Figure 5. Another important parameter of smooth particle motion in the separation process is the total motion period $t_{m}$, from drum supplied moment until the collecting, equations (13). This period is the sum of the periods, the drum seed motion period $t_{t}$ and free flight particle motion period $t_{c}$, when it is taken into consideration the air resistance.

$$
t_{m}=t_{t}+t_{c}
$$

The $t_{t}$ component it is obtained integrating the equation $d t=\frac{d \theta}{\dot{\theta}}$, in which $\dot{\theta}$ has the expression from equations (1), and its final shape is presented as equations (14).

$$
t_{t}=\int_{0}^{\theta_{0}}=\frac{d \theta}{\sqrt{c \cdot e^{-2 \mu_{d} \theta}+\frac{2 \mu_{d} a+b}{1+4 \mu_{d}^{2}} \sin \theta+\frac{2 \mu_{d} b-a}{1+4 \mu_{d}^{2}}} \cos \theta}
$$

The $t_{c}$ component is obtained integrating the equation $d t=\frac{v d \theta}{g \cos \theta}$ and its final form is equations (15) and the linear velocity is defined as in equations (16) [10].

$$
v=\frac{t_{c}=\frac{1}{g} \int_{\theta_{0}}^{\theta_{f}} \frac{v d \theta}{\cos \theta}}{\cos \theta \sqrt{\frac{1}{u_{p}^{2}}\left[\frac{\sin \theta}{\cos ^{2} \theta}+\ln t g\left(\frac{\theta}{2}+\frac{\pi}{4}\right)-\frac{1}{u_{p}^{2}}\left[\frac{\sin \theta_{0}}{\cos ^{2} \theta_{0}}+\ln \operatorname{tg}\left(\frac{\theta_{0}}{2}+\frac{\pi}{4}\right)\right]\right]}+\frac{1}{v_{0}^{2} \cos ^{2} \theta_{0}}}
$$

The particle motion period in free flight, marked with $t_{c^{\prime}}$, in the case in which is negated the air resistance, it was applied for the same constructive conditions $(y=h)$, and from equations (6) it is obtained the $x_{l}$ values for a specific angle $\theta_{0}$. Using the equations (17) are obtained the theoretical values of $t_{c}$, where $\theta_{f}$ it is obtained from equation (8).

$$
t_{c}{ }^{*}=\frac{x_{1}}{v_{0} \cos \theta_{0}}
$$

\section{RESULTS AND DISCUSSION}

Appling the mathematical models presented above for three common electromagnetic separation machines, present in the scientific literature, it was made a comparative study of seed trajectory depending on rotating drums characteristics, Table $1[5,6,11]$.

Table 1. The constructive characteristics of most representative electromagnetic separation machine.

\begin{tabular}{|c|c|c|}
\hline Machine type & Drum diameter $\varnothing[\mathrm{mm}]$ & Drum speed [rot $/ \mathrm{min}]$ \\
\hline MDS & 305 & 65 \\
\hline EMS - 1 & 468 & 53 \\
\hline GOMPPER & 610 & 50 \\
\hline
\end{tabular}

In this analyze, were taken into consideration three values of the friction coefficient $\mu=0.25,0.29,0.315$. For alfalfa seeds and clover, in almost all cases the floating velocity $u_{p}$ has values between 4 and $6.5[\mathrm{~m} / \mathrm{s}]$. 
The mathematical models were inserted the Mathcad numeric simulation program and in this way were obtained the detachment angle $\theta_{0}$ and the speeds $v_{0}=R \theta^{\prime}$, for each drum and for each friction coefficients $[1,7]$. Also, was intended determine drum particle movement taking into account the air resistance $t_{m}$ and neglected it $t_{m}$.

The numeric results obtained are presented in Table 2, in drum seed detachment moment depending on the function of friction coefficient for each drum, are presented in the graphs from Figures 5, 6 and 7.

Table 2. The simulation data obtained using the mathematical model.

\begin{tabular}{|c|c|c|c|c|c|}
\hline \multicolumn{6}{|c|}{ D $305[\mathrm{~mm}], \omega=6.81[\mathrm{rad} / \mathrm{s}]$} \\
\hline$\mu$ & $\dot{\theta}_{0}[\mathrm{rad} / \mathrm{s}]$ & $\theta_{0}\left[{ }^{0}\right]$ & $v_{0}[\mathrm{~m} / \mathrm{s}]$ & $t_{m}(\mathrm{~s})$ & $t_{m^{*}}{ }^{*}(\mathrm{~s})$ \\
\hline 0.25 & 6.89 & 43.95 & 1.051 & 0.493 & 0.492 \\
\hline 0.29 & 6.94 & 43.95 & 1.058 & 0.481 & 0.489 \\
\hline 0.315 & 6.96 & 43.95 & 1.061 & 0.475 & 0.471 \\
\hline \multicolumn{6}{|c|}{$\mathrm{D} 468[\mathrm{~mm}], \omega=5.23[\mathrm{rad} / \mathrm{s}]$} \\
\hline$\mu$ & $\dot{\theta}_{0}[\mathrm{rad} / \mathrm{s}]$ & $\theta_{0}\left[^{0}\right]$ & $v_{0}[\mathrm{~m} / \mathrm{s}]$ & $t_{m}(\mathrm{~s})$ & $t_{m^{*}}{ }^{*}(\mathrm{~s})$ \\
\hline 0.25 & 5.57 & 49.16 & 1.303 & 0.623 & 0.599 \\
\hline 0.29 & 5.6 & 49.16 & 1.31 & 0.604 & 0.582 \\
\hline 0.315 & 5.62 & 49.16 & 1.315 & 0.599 & 0.573 \\
\hline \multicolumn{6}{|c|}{$\mathrm{D} 610[\mathrm{~mm}], \omega=5.23[\mathrm{rad} / \mathrm{s}]$} \\
\hline$\mu$ & $\dot{\theta}_{0}[\mathrm{rad} / \mathrm{s}]$ & $\theta_{0}\left[{ }^{0}\right]$ & $v_{0}[\mathrm{~m} / \mathrm{s}]$ & $t_{m}(\mathrm{~s})$ & $t_{m^{*}}{ }^{(\mathrm{s})}$ \\
\hline 0.25 & 4.88 & 42.29 & 1.488 & 0.674 & 0.656 \\
\hline 0.29 & 4.91 & 41.521 & 1.498 & 0.665 & 0.636 \\
\hline 0.315 & 4.924 & 41.059 & 1.502 & 0.658 & 0.625 \\
\hline
\end{tabular}

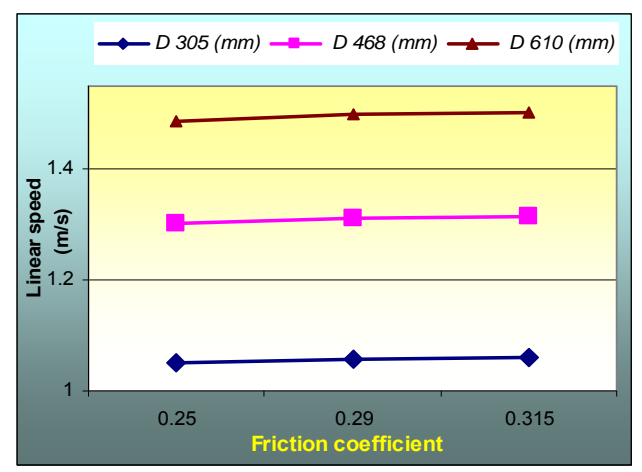

Fig. 5. The linear velocity dependency with friction coefficient.

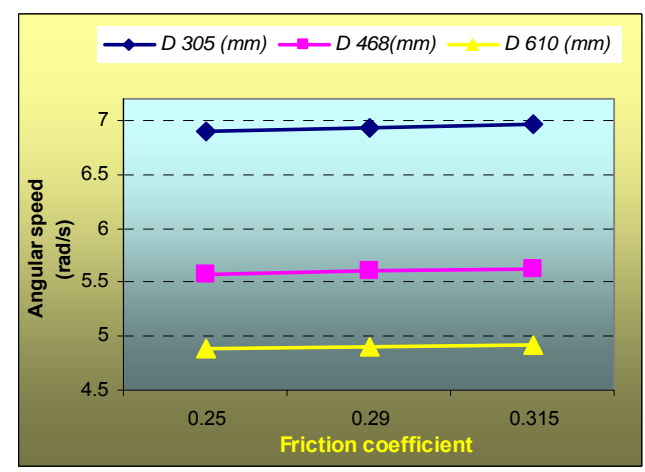

Fig. 6. The angular velocity dependency with friction coefficient.

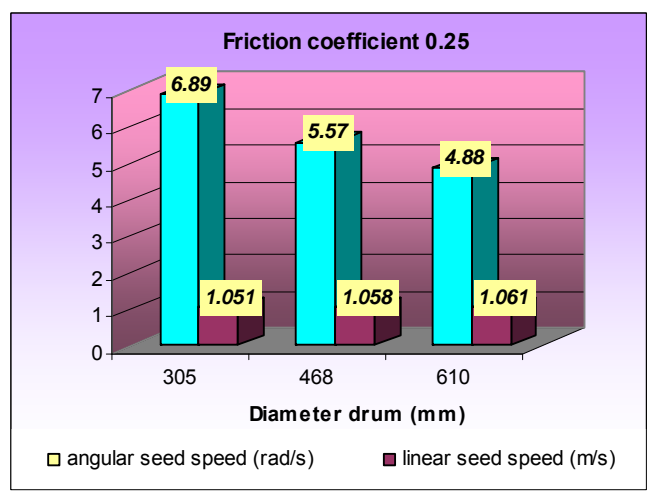

Fig. 7. The dependency of the linear and angular speed with drum diameter for the same friction coefficient.

Then were evaluated the detached seed collection points from the drum in the case of free fall in bought cases (neglecting and considering the air resistance) when $H$ is 150 [mm], a typical value for this type of machine [7]. 
Machine collection points were established based on the seed trajectories in free fall detached from the drum during the free fall after the seed was detached from the drum.

For this case were obtained $\theta_{0}$ and $v_{0}$ values, using the equations (1) and (4), and also the collector position using the equation (12). So were drawn the smooth seeds detached trajectories from the drum, neglecting and taking into account the air resistance, Figures 8 and 9, for each drum type and for the same friction coefficient $\mu_{d}=$ 0.29. As it can be noticed, the seeds free fall trajectories between those two situations did not differ significantly.

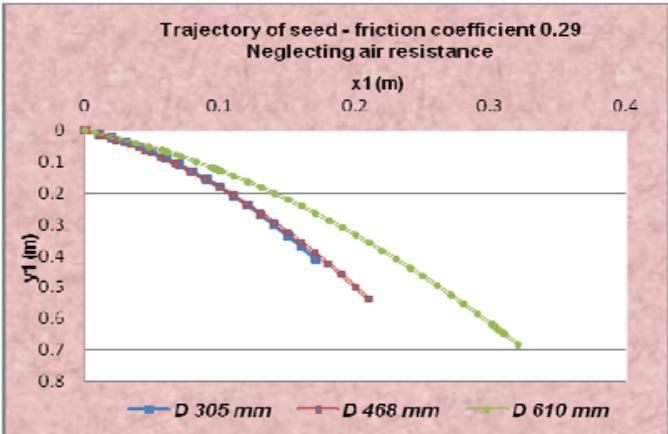

Fig. 8. The seed trajectory taking in into consideration the air resistance.

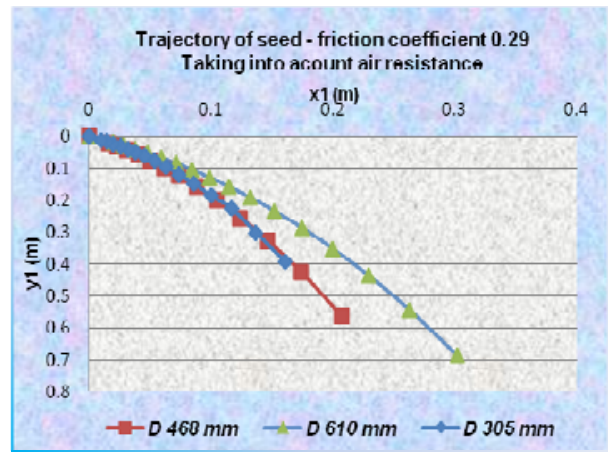

Fig. 9. The seed trajectory neglecting the air resistance.

From the graphical representation is observed that the trajectories of the seeds differ significantly, in each case, when is neglected or taking into account air resistance, these were removed by the vertical of the launching point with increasing speed drum.

The same calculations were made for friction coefficient $\mu_{d}=0.315$, and the obtained results are presented in Figures 10, 11 and 12. As it can be noticed, the difference between the seed free fall trajectories is not significant, and the air resistance has a small influence on those.

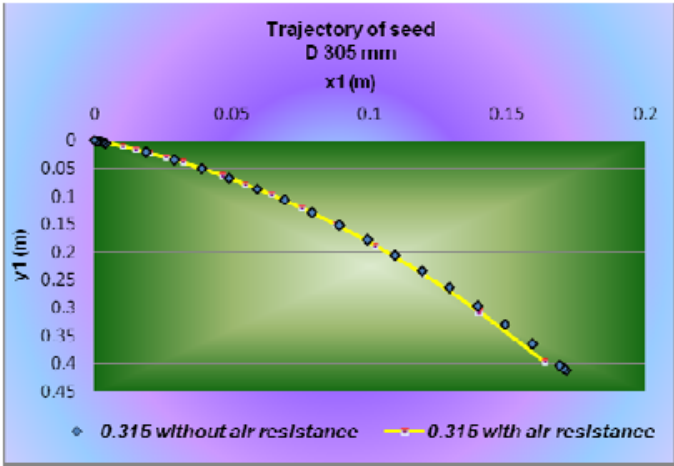

Fig. 10. Seed trajectory for the drum D 305 [mm].

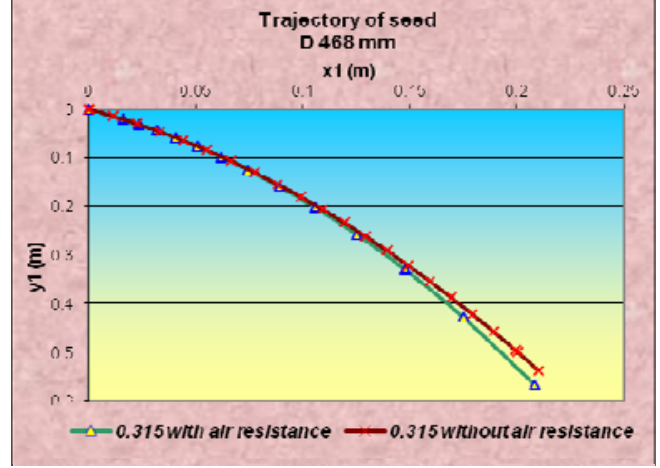

Fig. 11. Seed trajectory for the drum D 468 [mm].

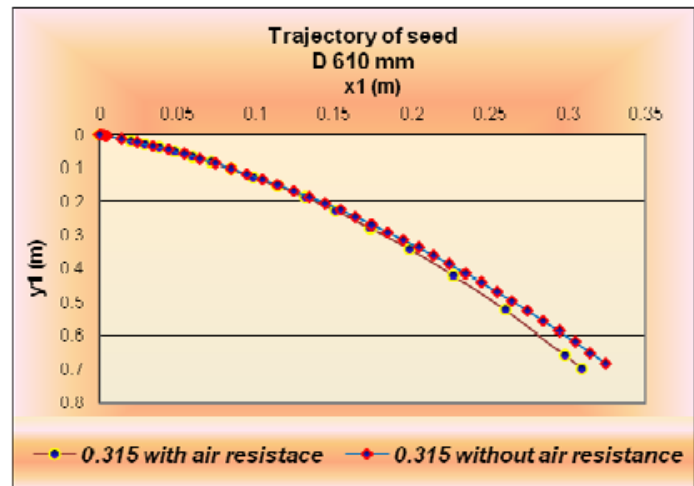

Fig. 12. Seed trajectory for the drum D 610 [mm]. 
Obtained data, regarding the seed collector position ( $h$ and $d$, from Figure 4 ) for those three drums and three friction coefficients, neglecting and taking into consideration the air resistance is presented in Table 3 . The parameter is considerate the real value for the cases presented [8].

Table 3 . The values of the seed collecting points detached from the rotary drum.

\begin{tabular}{|c|c|c|c|c|c|c|c|c|c|}
\hline \multicolumn{10}{|c|}{$305[\mathrm{~mm}], \omega=6.81[\mathrm{rad} / \mathrm{s}], \mathrm{H}=455[\mathrm{~mm}]$ Neglecting air resistance } \\
\hline$\mu$ & $h^{*}[\mathrm{~mm}]$ & $x_{1}[\mathrm{~mm}]$ & $d_{[\mathrm{mm}]}$ & $t_{c^{*}[\mathrm{~s}]}$ & $\mathrm{c}$ & $h_{[\mathrm{mm}]}$ & $x_{1}[\mathrm{~mm}]$ & $d_{[\mathrm{mm}]}$ & $t_{c}[\mathrm{~s}]$ \\
\hline 0.25 & 412.292 & 170.213 & 276.053 & 0.225 & -1.692 & 392.231 & 161.069 & 309.154 & 0.226 \\
\hline 0.29 & 412.292 & 171.063 & 276.269 & 0.2245 & -1.669 & 396.833 & 163.010 & 311.095 & 0.227 \\
\hline 0.315 & 412.292 & 171.429 & 276.903 & 0.2244 & -1.659 & 398.886 & 163.866 & 311.951 & 0.228 \\
\hline \multicolumn{10}{|c|}{$\mathrm{D} 468[\mathrm{~mm}], \omega=5.23[\mathrm{rad} / \mathrm{s}], \mathrm{H}=618[\mathrm{~mm}]$} \\
\hline 0.25 & 537.024 & 209.026 & 386.056 & 0.245 & -1.346 & 557.053 & 204.991 & 433.399 & 0.269 \\
\hline 0.29 & 537.024 & 209.821 & 386.851 & 0.2448 & -1.331 & 562.028 & 206.890 & 435.299 & 0.267 \\
\hline 0.315 & 537.024 & 210.401 & 387.431 & 0.2446 & -1.321 & 565.394 & 208.175 & 436.584 & 0.271 \\
\hline \multicolumn{10}{|c|}{$\mathrm{D} 610[\mathrm{~mm}], \omega=5.23[\mathrm{rad} / \mathrm{s}], \mathrm{H}=760[\mathrm{~mm}]$} \\
\hline 0.25 & 680.623 & 312.863 & 518.092 & 0.284 & -0.816 & 651.168 & 286.906 & 582.111 & 0.302 \\
\hline 0.29 & 683.357 & 320.266 & 522.449 & 0.285 & -0.787 & 686.459 & 302.084 & 597.515 & 0.314 \\
\hline 0.315 & 684.980 & 324.402 & 524.737 & 0.286 & -0.773 & 700.741 & 309.024 & 604.547 & 0.319 \\
\hline
\end{tabular}

$(*)$ The correct values.

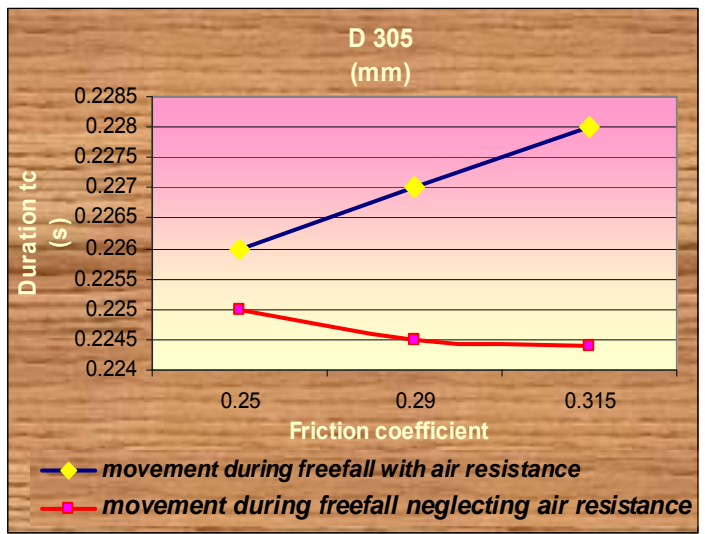

Fig. 13. The variation of the seed motion period during free flight phase depending on the friction coefficient.

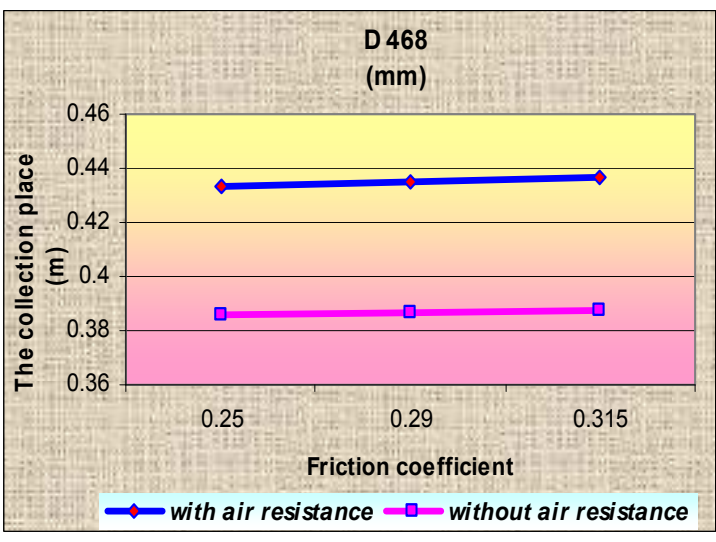

Fig. 14. The variation of the collector position depending on the air resistance.

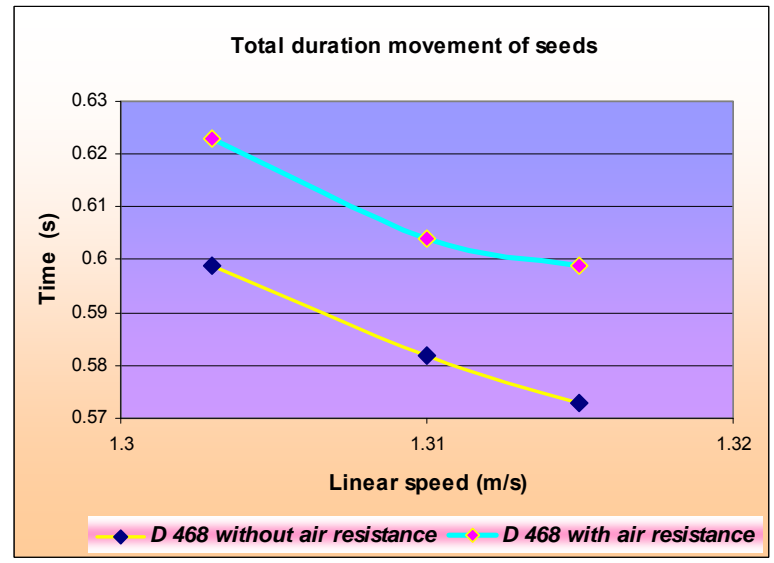

Fig. 15. Dependency of the total seeds motion time on linear speed.

Analyzing the data from Table 3, results that the collector position departs from the drum vertical axis along with drum diameter increase and also with friction coefficient increase. If we compare the data in terms of the 
influence of air resistance on constructive parameters, it can be observed from Figures 13,14 and 15 that it is an insignificant differences between them, which lead to the conclusion that the equations (5) and (6) can be successfully used to trace the seed trajectory and to establish the collector.

\section{CONCLUSIONS}

In this article was made a comparative analysis, from the theoretic point of view, of smooth seed motion on electromagnetic drum surface and of free fall trajectories, neglecting and taking into consideration the air resistance, for three working separation machines, that have different drum diameters and for a variety of friction coefficients.

Following numerical simulation it is noticed:

- The friction coefficient has a slight influence the angular and the linear velocity;

- The seed linear speed decreases slowly than the increase drum diameter, for the same friction coefficient;

- The difference between the seed free fall trajectories, taking in consideration and neglecting the air friction, are insignificant, which allows successful application of equation (6), that is simple and a friendly expression;

- The detached seeds collector position from the electromagnetic drum surface, with and without air friction, moves away from the vertical drum axis once with diameter increase, when the friction coefficient is constant;

- For the same drum diameter and friction coefficient, the smooth seed collector position is near to vertical drum axis, in bought cases - with and without air resistance;

- The smooth particle motion period on electromagnetic drum did not differ significantly for small drum diameters in those cases in which is taking into account the air resistance.

\section{REFERENCES}

[1] Bucurescu, N., Roman, D., Croitoru, P., Neguț, C., Sămânța și pregătirea acesteia pentru însămânțări, Editura Ceres, 1992, p. 130-131.

[2] David, G.R., Christy, L.S., Erin, C.T., Evaluation of Management Strategies for field dodder (cuscuta spp.) in Michigan Sugarbeet Production Systems, Michigan State University, Proceedings of the North Central Weed Science Society annual meeting, Milwaukee, WI, 2011.

[3] http://www.invasive.org/browse/detail.cfm?imgnum=5376402 (24.07.2015).

[4] http://itp.lucidcentral.org/id/fnw/key/FNW Seeds/Media/ Html/fact sheets/Cuscuta.htm (20.08.2015).

[5] Krasnicenko, A.V., Manualul constructorului de maşini agricole, Editura Tehnica, vol. 2, Bucureşti, 1964, p. $493-494$.

[6] Letosnev, M.N., Maşinii Agricole, Editura de Stat Agro-silvică, Bucureşti, 1959, p. 704-706.

[7] Căsăndroiu, T., Ciobanu, V., Moise, V., Vişan, A.L., Theoretic aspects of seed motion on drum surface of electromagnetic separation machines, Applied Mechanics and Materials, vol. 656, 2014, p. 305-314.

[8] Căsăndroiu, T., Ciobanu, V., Păun, A., Mathematical models for describing the seeds motion in separation processes, $43^{\text {rd }}$ International Symposium "Actual Tasks on Agricultural Engineering", 2015, Opatija, Croatia (to be published);

[9] Voinea, R., Voiculescu, D., Ceauşu, V., Mecanica, Editura Didactică si Pedagogică, Bucureşti, 1975.

[10] Neliubov, A.I., Vetrov, E.F., Pnemvmosepariruiuşcie sistemî selskohoziaistvenîh maşin. Maşinos troienie, p. 40-45, Moscova, 1977.

[11] Tiţ, Z.L., Maşinî dlia posleuborocinoi potocinoi obrabotki semian. Maşinostroienie, Moscova, 1967, p. 2729. 